\title{
THE EFFECT OF WOMEN ACADEMIC LEADERS ON CANADIAN NATURAL SCIENCES AND ENGINEERING PROFESSORS
}

\author{
JENNFER DENGATE \\ UNIVERSITY OF MANITOBA \\ RENÉE HOFFART
UNIVERSITY OF MANITOBA \\ $\mid$ \\ TRACEY PETER
UNIVERSITY OF MANITOBA \\ ANNEMIEKE FARENHORST
UNIVERSITY OF MANITOBA \\ TAMARA FRANZ-ODENDAAL \\ MOUNT SAINT VINCENT UNIVERSITY
}

\begin{abstract}
Using a sample of women natural sciences and engineering (NSE) faculty members from 13 Canadian universities, we investigated the impact of women academic leaders on women professors' perceptions of gender bias. Logistic regression analyses indicated that professors who perceived more workplace gender bias were more likely to feel that they needed to work harder to be seen as legitimate scholars than those who perceived less gender bias. However, professors who perceived that women were better represented amongst their faculty/college and university leadership were significantly less likely to feel that they needed to work harder for legitimacy than those who perceived greater gender bias in leadership. These results suggest that addressing gendered university hierarchies may moderate the impact of gender bias on women in NSE units.

Keywords: leadership, gender, professors, natural sciences, engineering, Canada

\section{Résumé}

Notre étude porte sur l'influence des femmes en position de leadership en milieu universitaire sur la perception des préjugés sexistes chez les professeures. L'échantillon étudié comporte des femmes du corps professoral en sciences naturelles et en génie (SNG) parmi 13 universités canadiennes. Des analyses fondées sur des régressions logistiques montrent que les professeures qui perçoivent davantage de préjugés sexistes en milieu de travail sentent qu'elles doivent travailler plus fort pour se sentir légitimes, comparativement à celles qui perçoivent moins ces mêmes préjugés. Toutefois, si le corps professoral et la direction comptent des femmes, les professeures ressentent beaucoup moins l'obligation de travailler plus fort pour se sentir légitimes, comparativement à celles qui perçoivent plus de préjugés au sein de la direction. Les résultats donnent à penser qu'une réflexion sur la hiérarchie genrée en milieu universitaire pourrait atténuer les effets des préjugés sexistes sur les femmes en SNG.

Mots-clés : leadership, genre, professeures, sciences naturelles, ingénierie, Canada
\end{abstract}

\section{Introduction}

There is an extensive literature describing gender biased workplace climates in academic science, technology, engineering, and mathematics (STEM) departments/ units (e.g., Fox, 2010; Settles et al., 2006). Women report experiencing a wide array of inequities relative to their male colleagues including less research support (Xu, 2008); a disproportionate responsibility for service and addressing students' personal problems (Dengate, Peter, \& Farenhorst, 2019; Misra et al., 2011); and harassment and uncivil treatment from colleagues and students (Clancy et al., 2017; Dengate, Peter, Farenhorst, \& Franz-Odendaal, 2019). 
In contrast, the extent and consequences of gender bias in academic leadership appears under-explored. Moreover, the impact of women academic leaders on women STEM professors' workplace experiences remains under-examined despite evidence that women leaders positively influence academic workplaces (Chesterman et al., 2003; Tomàs et al., 2010); and that women role models can help mitigate gender bias in STEM (Dasgupta, 2011; Stout et al., 2011). Studies of gender bias in STEM leadership tend to, instead, describe the barriers that aspiring women leaders encounter (McCullough, 2011); women STEM leaders' experiences, including in industry contexts (Marinelli \& Lord, 2014); initiatives to increase women's representation amongst academic leadership (Bilimoria \& Liang, 2014); or the characteristics of effective women academic leaders (Tomàs et al., 2010).

The gap in the literature around the impact of women leaders is unfortunate as existing evidence also suggests that there may be a relationship between women STEM professors' own experiences of gender bias (e.g., harassment) and the persistence of gender biased university hierarchies, where men occupy a disproportionate share of the most senior administrative positions (Smith \& Bray, 2017). Experiencing harassment has been associated with promotion delays for women natural sciences and engineering (NSE) professors in Canada (Dengate, Peter, Farenhorst, \& Franz-Odendaal, 2019); and dissatisfaction with research support and advancement opportunities has been linked to greater intentions to change jobs amongst women in STEM units in the United States (Xu, 2008). Accordingly, women STEM professors' disadvantage appears compounded; gender bias experiences can inhibit women from advancing to senior positions (McCullough, 2011), yet if more women did advance, they might help mitigate other women STEM professors' experience of workplace gender bias (Dasgupta, 2011; Stout et al., 2011).

Our objective is to add to the literature examining the impact of women in academic leadership (e.g., Chesterman et al., 2003; Tomàs et al., 2010). Using a sample of women NSE professors from 13 Canadian universities, we ask if perceiving that women are well-represented amongst faculty/college and university leadership has a moderating effect on respondents' perceptions of gender bias and feeling that they have to work harder to be perceived as a legitimate scholar.

\section{Canadian Context: Gendered Universities}

We situate our analysis within the gendered organizations framework, which asserts that organizations' structures can be biased against women, resting upon an unequal division of labour (Acker, 1990). Some scholars argue that universities are gendered organizations (e.g., Bird, 2011); and this literature tends to emphasize that underlying gender bias is reflected in women's greater responsibility for devalued service work (Bird et al., 2004) or hidden care labour, such as helping students with personal problems (Dengate, Peter, \& Farenhorst, 2019).

However, a gendered division of labour may also be observed in the composition of an organization's hierarchy; with men being overrepresented amongst senior leadership, for example (Acker, 1990). In such a hierarchy, women are less likely to hold powerful positions and more likely to perform supportive functions, emphasizing the perceived lower value of "women's work" (Acker, 1990). Even though university power is decentralized-distributed amongst the central administration and individual units including faculties/colleges and departments, each with their own leaders-men tend to hold a disproportionate number of senior positions across these units (Bird, 2011). Accordingly, to the extent that women are underrepresented across academic leadership, their ability to positively influence workplace cultures, including gender equity, is limited (Peter et al., 2020).

Consistent with the scholarship on universities as gendered organizations (Bird et al., 2004; Bird, 2011), academic NSE units in Canada tend to be male-dominated and have gendered hierarchies. Women accounted for less than $25 \%$ of full-time academic staff within architecture, engineering, mathematics, computer science, physical/life sciences, and technologies in 2016-2017 (Statistics Canada, 2018). Women in NSE disciplines are less likely than men to be full professors (Canadian Association of University Teachers, 2018); and comprised less than $10 \%$ of full professors in the physical sciences and engineering in 2011 (Natural Sciences and Engineering Research Council, 2017). Moreover, it may take significantly longer for women in NSE to be promoted to associate and full professor than men (Ornstein et al., 2007).

Canadian university administrations also appear to 
Table 1

Gender Diversity in U15 Leadership

\begin{tabular}{lccc}
\hline & Total Number & Women & Men \\
\hline President's Leadership Teams & 115 & $37.4 \%$ & $62.6 \%$ \\
Chancellors & 15 & $26.7 \%$ & $73.3 \%$ \\
Presidents & 15 & $20 \%$ & $80 \%$ \\
Provosts and VPs Academic & 15 & $40 \%$ & $60 \%$ \\
VPs Research & 15 & $40 \%$ & $60 \%$ \\
Deans & 212 & $31.1 \%$ & $68.9 \%$ \\
\hline
\end{tabular}

Source: Smith, M.S. (2017). Academic Women's Association, University of Alberta, Edmonton, April 2017; reproduced in Smith, M. S., \& Bray, N. (2017). Action needed to close the leadership diversity gap in Canadian universities. Academic Women's Association: University of Alberta.

be male-dominated. As illustrated in Table 1, leadership across the top 15 universities in Canada (the "U15") remains mostly male (Smith \& Bray, 2017). With respect to racial diversity, all of the (few) women chancellors and presidents were white, as were the vast majority of women vice provosts academic, vice provosts research, and deans (Smith \& Bray, 2017). Interestingly, the two U15 schools with the highest percentage of women deans (54\% and 50\%) were the only institutions with women presidents (Smith \& Bray, 2017), again fueling questions as to the broader effect that women academic leaders may have on gender equity.

\section{Literature Review}

Unfortunately, there is currently little direct evidence detailing the impact that women academic leaders have on professors' perceptions of gender bias. Nevertheless, the extant literature indicates that gender bias can impede women from advancing to leadership positions, and suggests that the quality of academic workplaces may suffer as a result of women's absence. Accordingly, previous research leads us to expect that women NSE professors who perceive greater gender equity amongst their faculty/college and university leadership will be less likely to feel that they have to work harder to be perceived as a legitimate scholar relative to their colleagues that perceive greater gender inequity in leadership.

We begin by discussing how cultural gender bias and organizational gender bias in universities can serve as barriers to academic/STEM leadership for women. We then explore the evidence describing the positive effect that women leaders can have on academic workplaces. Because our analysis inquires about gendered leadership at the faculty/college and university levels, we review studies involving women leaders from any discipline, but emphasize STEM-specific findings whenever possible.

\section{Gendered Barriers to Academic/STEM Leadership}

Women in academic science and engineering in the United States were more likely to hold a disciplinary leadership position (e.g., professional association), than a research centre or university administrative position (Parker \& Welch, 2013). To the extent that research centres and university leaders influence knowledge production and control resources (Parker \& Welch, 2013), a gendered division of leadership is problematic for gender equity in academic STEM and may, arguably, further embed gender bias in universities' structures.

Even though some women expressed little interest in leadership roles, such as dean (Dutta, 2018; Hart, 2016; Tomàs et al., 2010), women's so-called disinterest reflects constrained career choices. Women in STEM have the capability to lead (e.g., Dugan et al., 2013), but the combination of gendered cultural stereotypes and or- 
ganizational gender bias within universities may render them "unseen" with respect to leadership—not seen as a good fit by their institutions, with many women considering themselves to be a poor fit, too (Dutta, 2018, p. 244).

\section{Cultural Gender Bias}

Leadership roles are implicitly masculine-typed; assumed to require someone who is tough, assertive, and decisive. As cultural stereotypes typically associate men with these agentic attributes, there is no conflict between men's gender and leadership (Eagly \& Karau, 2002; HeiIman, 2001). However, role incongruity exists for women leaders because they violate descriptive stereotypes of feminine communality (e.g., women are deferential, not assertive). Thus, there is a perceived lack-of-fit between women and leadership positions (Eagly \& Karau, 2002; Heilman, 2001). Moreover, the more masculine-typed the job (e.g., Dean of Science), the worse the perceived fit and the greater the expectations that women will fail (Heilman, 2001, p. 660).

Indeed, women professors may feel pressure to exhibit stereotypical feminine traits at work, such as passivity and cooperation (Dutta, 2018; McCullough, 2011; Tomàs et al., 2010). As these traits are inconsistent with stereotypically masculine understandings of leadership, women may undervalue their own abilities; and state that they "do not feel ready" or qualified for leadership (Chesterman et al., 2003, p. 245; Dutta, 2018; Roos \& Gatta, 2009). Similarly, gender stereotypes around self-promotion may mean that women are not considered for leadership as often as men. Because bragging is less acceptable for women than men, women who self-promote in pursuit of advancement may experience backlash (Marinelli \& Lord, 2014; Moss-Racusin \& Rudman, 2010).

Gendered cultural expectations also influence the division of unpaid labour, such as caregiving and household chores. Consequently, some women may not be interested in (or considered for) leadership related to their disproportionate responsibility for domestic labour, which may already make it difficult to balance family and an academic workload (Brue, 2019; Dutta, 2018; McCullough, 2011; Rosser, 2004).

Likewise, masculine ideal worker expectations of an uninterrupted linear academic career (e.g., no caregiving leave) and mobility can put prospective women leaders at a disadvantage compared to men. Women professors in Australia were relatively less able to relo- cate or to change institutions than men for family-related reasons, which restricts their leadership opportunities (Chesterman et al., 2003).

\section{Organizational Gender Bias}

In addition to cultural stereotypes around leadership suitability, gender bias embedded within universities' structures can discourage women from pursuing (or being selected for) leadership roles; and such biases are reflected in the division of academic labour, access to networks and information, existing leadership composition (i.e., predominately men), and hiring processes.

With respect to division of labour, women may already be disproportionately responsible for academic service and student care work (e.g., helping with personal problems), which require significant time and effort (Dengate, Peter, \& Farenhorst, 2019; Misra et al., 2011). As a result, women STEM professors may consider leadership to be yet another distraction from research that they love (Hart, 2016); and which is most essential for career success (Acker et al., 2012).

Further, "old boys" networks influence informal decision making and information sharing in academia/STEM (Roos \& Gatta, 2009; Sagebiel, 2018). Indeed, Hart (2016) has noted that a critical function of STEM networks is the exchange of informal resources, including funding opportunities and inside information about department-specific matters. Thus, if excluded from informal networks and outings (e.g., beers, dinners, and golf), women may be less likely than men to obtain positions of STEM departmental influence (e.g., chair of major committees), or receive information to successfully compete for and perform leadership roles (Roos \& Gatta, 2009; Sagebiel, 2018).

Women's interest in and ascent to leadership may be further inhibited by the continued lack of women university leaders, overall. Without existing role models, it is difficult to challenge assumptions that women are ill-suited to lead (Ely et al., 2011; McCullough, 2011). Early-career STEM women in the United States (graduate students and postdocs) reported that they lacked options for formal mentors who could provide guidance for obtaining leadership roles and personal growth (Amon, 2017). Instead, some women looked for mentorship outside of their field in order to meet their needs (Amon, 2017). Similarly, Marinelli and Lord (2014, p. 102) found that women's decisions to transition to management in technical engineering organizations in Australia were of- 
ten facilitated by others (e.g., a manager seeking a temporary replacement). Thus, a persistent lack of women leaders to offer guidance or advocate for other women to fill open positions both reflects and helps maintain gender bias in organizational leadership.

Finally, evidence from the United States suggests that leadership candidates (e.g., for university/college president) tend to be sought via external national or international searches (e.g., Barden, 2010; Blumenstyk, 2005). Accordingly, the absence of initiatives designed to develop a supply of internal candidates (e.g., Bilimoria \& Liang, 2014; Luna, 2012), means that existing hiring practices can be an additional barrier to leadership for qualified and interested women professors. Similarly, mid-career women STEM professors in the United States felt that the path to leadership was ambiguous and that they received little institutional support for their leadership ambitions (Hart, 2016). Consequently, some felt that changing universities was their only option (Hart, 2016).

In sum, cultural stereotypes and organizational gender bias may combine to impede women's ascent to leadership positions in academia, including STEM units (McCullough, 2011; Roos \& Gatta, 2009). To underscore the impact of gender inequity in academic leadership, we now turn to the positive effect that women leaders may have on academic workplaces (Tomàs et al., 2010), including mitigating women's experiences of gender bias in STEM units (Dasgupta, 2011; Stout et al., 2011).

\section{Effect of Women Academic Leaders}

The literature suggests that academic workplace cultures benefit from women leaders. Specifically, Australian academic cultures became more friendly, supportive, and collegial when women held positions with significant power (Chesterman et al., 2003). Similarly, women university leaders in Spain were credited with effectively supervising programs, reducing bureaucracy, addressing employees' needs, and creating a positive work atmosphere (Tomàs et al., 2010, p. 496). Even though more research is needed to understand exactly why women leaders have a positive effect, some literature suggests that their impact could be related to adopting the transformational style of leadership, which is consistent with some stereotypically feminine communal behaviours, such as supporting others and working together (Eagly \& Johannesen-Schmidt, 2001).

Indeed, women academic leaders in Spain assert- ed that the most important leadership attributes included a genuine concern for addressing people's needs, creating a positive atmosphere, and a strong commitment to teamwork (Tomàs et al., 2010). They emphasized acknowledging workers' efforts, making sure that everyone's ideas were included, promoting dialogue, reaching consensus, and transparent decision making (Tomàs et al., 2010). Similarly, women academic leaders in Australia emphasized working with staff and students, encouraging them to develop, and highlighted the importance of collaboration and consultation as opposed to hierarchical management (Chesterman et al., 2003, p. 432; Tomàs et al., 2010). However, any positive impact attributed to the transformational style may come at a cost; adopting a communal leadership style also risks that women will be considered less competent, given expectations that leaders should be dominant and agentic (Rudman et al., 2012).

There is some evidence that women in academic STEM value transformational leadership (Amon, 2017). However, women STEM leaders also combined agentic and communal behaviours (Isaac et al., 2010), including strategically employing each at different times, perhaps to ensure they are perceived as competent leaders in fields traditionally dominated by men while also remaining likeable by not losing too much of their femininity (Faulkner, 2009).

Early-career women in academic STEM navigated being a motherly figure or an authoritative "b-word" (Amon, 2017). When working with men, one woman recalled hiding emotions and not being too soft. With women, emphasizing equality and emotion was a more effective approach (Amon, 2017). Similarly, women engineering managers in Australia adopted an androgynous style (i.e., both relational and instrumental qualities) to transition to leadership, but emphasized people and relationships once they were managers, including prioritizing employees' development and well-being to build effective teams (Marinelli \& Lord, 2014). Accordingly, women STEM leaders may have to engage in an additional balancing act to be maximally effective, as compared to women leading different university units.

\section{Effect on Other Women in STEM}

Women leaders can have a positive effect on other women professors. Women professors may be more comfortable sharing their insecurities with women leaders as they may feel women are less likely to judge them 
than men, perhaps related to shared struggles and work experiences (Burke \& McKeen, 1996; Chesterman et al., 2003). With respect to STEM units, three women chairs in medicine in the United States were proudly viewed by other women and men professors as indicators of positive change (Isaac et al., 2010). Likewise, women STEM professors reported greater feelings of empowerment and influence in their department after working with a woman mentor (Settles et al., 2007).

Even though more STEM-specific research is needed to draw conclusions regarding explanatory processes, some social psychological studies indirectly suggest that women leaders may help other women STEM professors overcome experiences of gender bias because these women serve as reminders that women belong in STEM. Specifically, women role models helped increase other women's sense of belonging and self-efficacy; and greater belonging and self-efficacy were, in turn, associated with decreased perceptions of bias (Dasgupta, 2011). Extrapolating from these findings, women leaders may help to protect other women from the negative effects of gendered stereotypes about STEM and leadership competence, perhaps (Dasgupta, 2011; Stout et al., 2011).

Frequent, high-quality interactions with successful women professors were associated with greater career ambitions and leadership self-concept amongst women university students (Asgari et al., 2010). However, perceived similarity appeared key. Women students who were exposed to women leaders who were similar to them (i.e., told that both had graduated from the same university) were less vulnerable to leadership stereotypes; seeing themselves as having more leader-like qualities than those who were exposed to women leaders that were dissimilar to them (Asgari et al., 2011, pp. 379-380).

In addition, an inclusive style of leadership (to the extent that women lead inclusively) might also help foster an "identity-safe environment," which assures individuals that potentially stigmatizing identities, like gender or race, are not barriers to success and that marginalized individuals are welcomed and supported (Davies et al., 2005 , p. 278). Identity-safe conditions reduced vulnerability to stereotype threat (i.e., expectations of failure that undermine actual performance). When women were informed that gender differences in leadership skills did not exist, they were no longer significantly more likely to choose a supportive role over a leadership role (Davies et al., 2005).
Accordingly, a greater number of women leaders and increasing the quantity and quality of women STEM professors' contact with these leaders may help mitigate the effect of gender bias; and possibly enhance women own estimation of their fit for leadership, especially if they see similarities between themselves and women leaders (Asgari et al., 2010, 2011; Dasgupta, 2011; Stout et al., 2011). As such, we expect that women NSE professors who perceive that women are better represented amongst their faculty/college and university leadership will be less likely to feel that they need to work harder to be perceived as a legitimate scholar, relative to their counterparts that perceive greater gender inequity in leadership.

\section{Methodology}

We administered a workplace experiences survey to NSE professors from 13 Canadian universities located across the Prairie and Atlantic provinces. Data collection from five Prairie universities took place between September and November 2017; and data collection from eight Atlantic universities took place between April and June 2018. We compiled a list of professors' email addresses from university websites to create the sampling frame and invited them to participate via email. The survey covered a number of topics pertaining to workplace climate, including workload fairness, harassment/ discrimination, and leadership support.

\section{Sample}

The final size of the full sample (men and women) after data cleaning was 686 respondents, constituting a response rate of $22 \%$. Approximately one-third of the full sample are women (36.3\%) and $63.7 \%$ are men. As we are interested in the effects of gendered leadership on women, this analysis only includes the female respondents $(n=192)$. We present a comparison of demographic characteristics for the full and women-only samples in Table 2.

\section{Measures}

The independent variable is an index of perceived bias toward women. We performed a factor analysis on 11 items, which indicated that all items measured the same concept. The full list of items can be found in Table 3 below. 


\section{Table 2}

Descriptive Statistics for Women-Only and Full Samples

\begin{tabular}{lcc}
\hline & Women-Only & Full (women and men) \\
\hline Mean age (years) & 47.4 & 49.4 \\
Self-identified as white & $89.1 \%$ & $86 \%$ \\
Full Professor & $40 \%$ & $46.7 \%$ \\
Teaching stream & $17.4 \%$ & $10.5 \%$ \\
Tenured & $70.6 \%$ & $75.3 \%$ \\
From Faculty of Science & $66.1 \%$ & $59.7 \%$ \\
From Faculty of Engineering & $13.5 \%$ & $20.3 \%$ \\
Senior administrative position (Associate Head/Chair or higher) & $19.5 \%{ }^{*}$ & $17.4 \%$ \\
Total sample size (n) & 192 & 686 \\
\hline
\end{tabular}

Note. *Of these women, $37.8 \%$ held a central or faculty-level administrative position; and $62.2 \%$ held a department- or unit-level position.

\section{Table 3}

Index of Perceived Bias Toward Women

1. My colleagues expect me to represent the 'point of view' of my gender

2. Stereotypes about women have affected me personally at work

3. I feel judged by my colleagues because I am female

4. In my faculty/college, many men have a lot of prejudice against women, even if they do not actually express them

5. At this university, most men have problems viewing women as equal

6. I believe that my colleagues' evaluations of me is affected by my gender

7. In my department/unit, I have raised a point, which was not listened to until it was later made by a male colleague

8. The increasing focus of granting agencies (e.g., NSERC, CIHR) on gender equity has resulted in men including collaborators on research grants that they would really prefer not to work with

9. Women who apply for research grants (e.g., NSERC, CIHR) have an advantage over their male peers because of granting agencies' policies on gender equity 
10. The recent announcement by Minister Duncan [Minister of Science for the federal government 2015-2019] for universities to meet gender diversity equity targets among Canada Research Chairs discriminates against white men

11. I feel that I am asked to serve on some committees just to meet diversity targets

Note. 5-point Likert response values ( 0 = strongly disagree, $4=$ strongly agree).

Reliability statistics $(\alpha=0.85)$ indicated a high level of internal consistency, meaning that the items were sufficiently related to one another to form a reliable index. Women's average score on the bias index was 31.16 out of 44, indicating a moderate level of perceived bias toward women $(M=31.16, S D=8.97)$.

\section{Dependent Variable}

The main dependent variable is the probability of agreeing with the following statement: I feel like I have to work harder to be perceived as legitimate (yes $=50 \%$, no $=$ $50 \%)$.

\section{Moderator Variable}

An index of women in leadership serves as the moderator variable. This index includes two items, asking respondents their level of agreement with the following: women are well-represented in leadership positions in my faculty/college; and women are well-represented in leadership positions at my university $(0=$ strongly disagree, 4 = strongly agree).

A Pearson's correlation indicated a strong relationship between the two items $(r=0.65)$; and mean scores suggested that respondents do not generally feel that women are well-represented amongst leadership within their faculty/college or university $(M=3.15, S D=1.02)$.

\section{Analysis Procedures}

As our dependent variable is dichotomous, we performed a logistic regression using SPSS v.25. To aid interpretation, we standardized the perceived bias and leadership indices around Z-scores values $(M=0, S D=$ 1). Scores above zero indicate above average perceived bias, whereas scores below zero indicate below average perceived bias, for example.

\section{Results}

The logistic regression results are shown in Table 4. Women who perceived more gender bias were 1.77 times more likely to agree that they have to work harder to be perceived as a legitimate scholar than those who perceived less bias. Perceptions of the number of women in leadership did not significantly impact women professors' feeling that they need to work harder to be perceived as legitimate.

With respect to rank, a chi-square analysis indicated that women associate professors $(72.3 \%)$ were significantly more likely than their assistant professor (45.5\%) and full professor (40\%) colleagues to agree that they needed to work harder to be perceived as legitimate $\left(\mathrm{X}^{2}\right.$ $(3,188)=12.67, p<.01)$. When we entered rank into the logistic regression equation alongside the gender bias covariate, we found a significant difference between associate and full professors, specifically. It makes sense that women associate professors are more likely to agree that they have to work harder to be perceived as legitimate scholars than full professors, as associate professors have not yet been promoted to the highest faculty rank.

When the interaction term between perceived bias and women in leadership was entered in the equation, we observed a significant relationship with the outcome measure. Our results indicated that the association between perceived gender bias and feeling like you have to work harder to be perceived as legitimate was moderated by women in leadership positions. Figure 1 shows that the slope is flatter where the moderator variable is present, indicating that women are less likely to feel that they have to work harder to be perceived as legitimate when more women are (perceived to be) in leadership positions. Alternatively, where the moderator is absent, the slope is steeper, which suggests that women feel they have to work harder for legitimacy (i.e., experience the impacts of gender bias more strongly) when they feel that women are relatively more absent from leadership. 


\section{Table 4}

Logistic Regression Results for "Working hard to be perceived as a legitimate scholar"

\begin{tabular}{lllllll}
\hline Variables & $\mathrm{b}$ & $\mathrm{OR}$ & $95 \% \mathrm{Cl}$ & $\mathrm{b}$ & $\mathrm{OR}$ & $95 \% \mathrm{Cl}$ \\
\hline Constant & $-.453(.254)$ & .636 & - & $-.644(.276)$ & .525 & - \\
Perceived bias & $.573(.184)^{* *}$ & 1.773 & $1.24-2.55$ & $.586(.191)^{* *}$ & 1.796 & $1.24-2.61$ \\
Women in leadership positions & $.061(.174)$ & 1.063 & $.76-1.50$ & $.011(.180)$ & 1.011 & $.71-1.44$ \\
Rank: Associate & $1.350^{* *}(.422)$ & 3.858 & $1.69-8.81$ & $1.463^{* *}(.433)$ & 4.318 & $1.85-10.1$ \\
Rank: Assistant & $.220(.439)$ & 1.247 & $.53-2.95$ & $.336(.449)$ & 1.399 & $.58-3.37$ \\
Rank: Instructor & $.543(.452)$ & 1.722 & $.71-4.18$ & $.524(.453)$ & 1.689 & $.70-4.10$ \\
Perceived bias X Leadership & & & & $.376(.178)^{*}$ & 1.456 & $1.03-2.06$ \\
\hline
\end{tabular}

${ }^{*} p<.05,{ }^{* *} p<.01,{ }^{* * *} p<.001$

Note: Full Professor is the comparison category for the variable rank.

Figure 1

Effect of Women Leaders on Scholarly Legitimacy and Perceived Bias

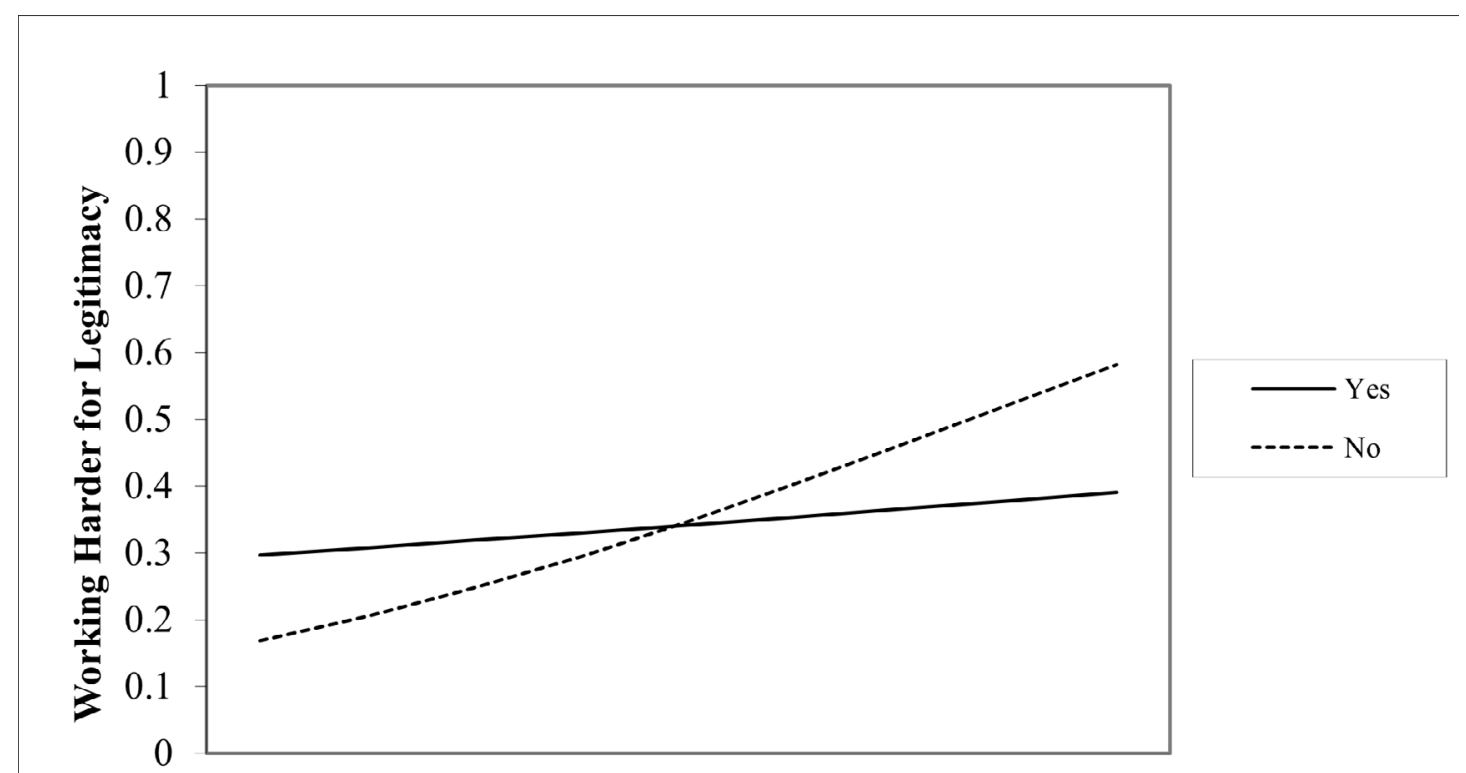

Low Perceived Gender Bias

High Perceived Gender Bias

The significant difference between associate and full professors held following the introduction of the interaction term. As such, our results suggest that the relationship between perceived gender bias and feeling like one has to work harder to be perceived as a legitimate scholar holds across all rank levels, but is particularly pronounced amongst women associate professors. 


\section{Discussion}

The literature indicates that gender bias inhibits women's advancement into academic/STEM leadership (McCullough, 2011); and that this is especially unfortunate because women role models may help mitigate the impact that gender bias in STEM has on other women (Dasgupta, 2011; Stout et al., 2011). We add to the literature on the impact of women academic leaders with our finding that perceiving a greater number of women leaders moderates the impact that gender bias has on women NSE professors' feeling that they need to work harder for scholarly legitimacy.

Moreover, existing research has established a link between women STEM professors' experiences of gender bias and the maintenance of gendered university hierarchies. Women NSE professors in Canada who reported harassment also reported delayed promotion to the associate professor rank (Dengate, Peter, Farenhorst, \& Franz-Odendaal, 2019); and dissatisfaction with research support was associated with greater intentions to change jobs amongst women STEM professors in the United States (Xu, 2008). Similarly, our results suggest that increasing women's representation amongst leadership may have a diffuse positive effect on women's perceptions of their NSE work environments.

Conversely, maintaining gendered hierarchies may exacerbate the impact of gender bias on women professors, perhaps including their confidence that women can advance to senior positions. Perceiving a lower likelihood of advancement opportunities and/or greater gender bias may, in turn, undermine women's commitment to their STEM employers (e.g., Settles et al., 2007; Major et al., 2013). As we found that women associate NSE professors who perceived gender bias were especially likely to feel that they needed to work harder for scholarly legitimacy, future research should prioritize investigating these women's level of career satisfaction and intent to change jobs to assess the risk of losing mid-career women as a result of persistent gender bias in academia.

\section{Implications for University Gender Equity Initiatives}

The literature suggests that the positive impact of women leaders on women NSE professors may be more pronounced if the quantity and quality of interactions between these two groups can be increased (Asgari et al., 2010, 2011; Chesterman, 2003). To illustrate, work teams might provide a space for women to discuss professional matters while also bolstering their sense of belonging, commitment to the workplace, and feelings of self-efficacy (Dasgupta, 2011). Likewise, formal and informal mentorship programs may increase connections and enable women to share experiences and advice.

Yet, the relatively low numbers of women in both senior leadership and in many NSE units may make it difficult to facilitate such interactions (e.g., Amon, 2017; Marinelli \& Lord, 2014). Indeed, women professors have often relied on external professional STEM networks, which may not support academic advancement if they are largely composed of non-academics (Sagebiel, 2018). Consequently, developing cross-university initiatives may provide women with access to a greater number of women administrators/senior NSE professor role models and facilitate the positive effect of women leaders.

Moreover, identifying diverse women role models may give women NSE professors with multiple marginalized identities greater access to women who share these same identities, which they (likely) lack (Asgari et al., 2011; Stenken \& Zajicek, 2010). Facilitating interactions amongst minority identity academic women may help NSE professors deal with the intersecting biases that they may be encountering and remind them that they, too, belong in NSE units (e.g., Davies et al., 2005). Further, access to more role models may illuminate different paths to academic leadership, which could reduce the need for aspiring women NSE leaders to change universities in pursuit of advancement (Hart, 2016).

\section{Limitations and Future Research on the Impact of Diverse Leaders}

Many of the limitations of this study can be addressed by future research. First, our measure of women's representation amongst leadership was based on perceptions, rather than actual numbers of women leaders within respondents' institutions. Future studies should account for the proportion of women leaders to better understand how degrees of gender bias in leadership may affect women NSE professors. Similarly, future studies should test which positions have a stronger effect and why. Do faculty/college leaders have a greater impact on per- 
ceptions of bias than university leaders? Is it because professors are more likely to have a greater number of interactions with leaders in their own unit (Asgari et al., 2010)? Is there a greater sense of similarity with faculty/ college leaders related to a shared discipline (Asgari et al., 2011)?

Indeed, we are unable to comment on the reasons why perceiving greater gender equity in leadership has a positive impact, even though it is logical to infer that those respondents who perceive greater gender equity in leadership may be more likely to feel that women belong; and that, therefore, these women respondents will also be less likely to feel that they need to work harder for legitimacy. Future research incorporating open-ended survey questions or interviews would enable women professors to better explain the connections amongst these variables, such as whether women leaders have improved the overall workplace environment and if improvements stem from their leadership style, for example (Isaac et al., 2010; Tomàs et al., 2010).

Our results cannot be generalized to all Canadian NSE professors, as our cross-sectional survey only sampled from two geographic regions and the response rate was somewhat low (22\%). A representative survey would clarify the extent to which women leaders have a positive effect on NSE professors; and a longitudinal design would be ideal for tracking changes in the number of women leaders and any corresponding changes in the degree of gender bias within NSE units.

A larger sample size is crucial going forward, as it would permit investigations of intersectional differences amongst underrepresented groups of NSE professors and academic leaders in Canada. Our sample was too small to sub-divide women professors and, as such, we could not observe whether women leaders positively impacted white and racialized women NSE professors equally, for example. Moreover, given that white women may be more likely to occupy leadership roles in Canadian academia than racialized women (Smith \& Bray, 2017), it will be important for future studies to disaggregate the impact of different women leaders on certain groups of professors (e.g., the effect of racialized women leaders vs. white women leaders on racialized NSE professors' experiences).

Lastly, a larger sample is necessary to move beyond gender to examine the impact of leaders on other types of bias in STEM units, including intersecting biases; for example, do LGBTQA leaders mitigate LGBTQA professors' experiences of heteronormative bias to a greater extent than other types of leaders and, if so, do racialized LGBTQA professors benefit as much as white LGBTQA professors?

\section{Conclusion}

Our analysis suggests that there may be far-reaching benefits of improving gender equity in academic leadership in Canada and that this topic must be a priority for future research on EDI in STEM units. In addition to enhancing institution-wide EDI by increasing women's share of senior faculty/college and university leadership positions, women leaders may also lessen the impact of gender biased NSE workplace climates on women professors. Women NSE professors are significantly more likely than men to encounter gender-based discrimination and mistreatment at work, which undermines their career achievement (Dengate, Peter, \& Farenhorst, 2019), women leaders may play a key role in mitigating systemic gender bias in STEM at multiple levels.

\section{Acknowledgements}

The authors are grateful to the anonymous reviewers for their comments and suggestions; and would like to thank the Natural Sciences and Engineering Research Council's Women in Sciences and Engineering Program for supporting this research.

\section{References}

Acker, J. (1990). Hierarchies, jobs, bodies: A theory of gendered organizations. Gender \& Society, 4(2), 139-158. https://doi. org/10.1177/089124390004002002

Acker, S., Webber, M., \& Smyth, E. (2012). Tenure troubles and equity matters in Canadian academe. British Journal of Sociology of Education, 33(5), 743-761. https://doi.org/10.1080/01425692.2012.6 $\underline{74784}$

Amon, M. J. (2017). Looking through the glass ceiling: A qualitative study of STEM women's career narratives. Frontiers in Psychology, 8, 1-10. https://doi. org/10.3389/psyg.2017.00236 
Asgari, S., Dasgupta, N., \& Gilbert Cote, N. (2010). When does contact with successful ingroup members change self-stereotypes? Social Psychology, 41(3), 203-211. https://www.doi.og/10.1027/1864$\underline{9335 / \mathrm{a} 000028}$

Asgari, S., Dasgupta, N., \& Stout, J. G. (2011). When do counterstereotypic ingroup members inspire versus deflate? The effect of successful professional women on young women's leadership self-confidence. Personality and Social Psychology Bulletin, 38(3), 370-383. https://www.doi. org/10.1177/0146167211431968

Barden, D. M. (2010). Where will you find your future leaders? Chronicle of Higher Education, 56(17), D20-D20.

Bilimoria, D., \& Liang, X. (2014). Effective practices to increase women's participation, advancement and leadership in U.S. academic STEM. In D. Bilimoria \& L. Lord (Eds.), Women in STEM careers: International perspectives on increasing workforce participation, advancement and leadership (pp. 146-165). Edward Elgar.

Bird, S. (2011). Unsettling universities' incongruous, gendered bureaucratic structures: A case-study approach. Gender, Work and Organization, 18(2), 202-230. https://doi.org/10.1111/j.14680432.2009.00510.x

Bird, S., Litt, J., \& Wang, Y. (2004). Creating status of women reports: Institutional housekeeping as "women's work." NWSA Journal, 16(1), 194-206. https://www.jstor.org/stable/4317042

Blumenstyk, G. (2005). Outside chance for insiders. Chronicle of Higher Education, 52(11), A28-A29.

Brue, K. L. (2019). Work-life balance for women in STEM leadership. Journal of Leadership Education, 18(2), 32-52. https://doi.org/10.12806/V18/I2/R3

Burke, R. J., \& McKeen, C. A. (1996). Do women at the top make a difference? Gender proportions and the experiences of managerial and professional women. Human Relations, 49(8), 1093-1104.

Canadian Association of University Teachers. (2018). Underrepresented \& underpaid: Diversity and equity among Canada's post-secondary education teachers. https://www.caut.ca/site/default/files/ caut equity report 2018-04final.pdf

Chesterman, C., Ross-Smith, A., \& Peters, M. (2003). Changing the landscape? Women in academic leadership in Australia. McGill Journal of Education, 38(3), 421-435.

Clancy, K. B. H., Lee, K. M. N., Rodgers, E. M., \& Richey, C. (2017). Double jeopardy in astronomy and planetary science: Women of color face greater risks of gendered and racial harassment. Journal of Geophysical Research: Planets, 122(7), 1610-1623.

Dasgupta, N. (2011). Ingroup experts and peers as social vaccines who inoculate the self-concept: The stereotype inoculation model. Psychological Inquiry, 22(4), 231-246. https://doi.org/10.1080/104 7840X.2011.607313

Davies, P. G., Spencer, S. J., \& Steele, C. M. (2005). Clearing the air: Identity safety moderates the effects of stereotype threat on women's leadership aspirations. Journal of Personality and Social Psychology, 88(2), 276-287. https://www.doi. org/10.1037/0022-3514.88.2.276

Dengate, J., Peter, T., \& Farenhorst, A. (2019). Gender and the faculty care gap: "The obvious go-to person" for Canadian university students' personal problems. Canadian Journal of Higher Education, 49(3), 104-114.

Dengate, J., Peter, T., Farenhorst, A., \& FranzOdendaal, T. A. (2019). Selective incivility, harassment, and discrimination in Canadian sciences \& engineering: A sociological approach. International Journal of Gender, Science \& Technology, 11(2), 332-353.

Dugan, J. P., Fath, K. Q., Howes, S. D., Lavelle, K. R. \& Polanin, J. R. (2013). Developing the leadership capacity and leader efficacy of college women in science, engineering, technology, and math fields. Journal of Leadership Studies, 7(3), 6-23, https:Il doi.org/10.1002/jls.21292

Dutta, D. (2018). Women's discourses of leadership in STEM organizations in Singapore: Negotiating sociocultural and organizational norms. Management 
Communication Quarterly, 32(2), 233-249. https:// doi.org/org/10.1177/0893318917731537

Eagly, A. H., \& Johannesen-Schmidt, M. C. (2001). The leadership styles of women and men. Journal of Social Issues, 57(4), 781-797.

Eagly, A. H. \& Karau, S. J. (2002). Role congruity theory of prejudice toward women leaders. Psychological Review, 109(3), 573-598. https://www.doi. org/10.1037//0033-295X.109.3.573

Ely, R. J., Ibarra, H., \& Kolb, D. (2011). Taking gender into account: Theory and design for women's leadership development programs. Academy of Management Learning \& Education, 10, 474-493.

Faulkner, W. (2009). Doing gender in engineering workplace cultures. II. Gender in/authenticity and the in/ visibility paradox. Engineering Studies, 1(3), 169189. https://doi.org/10.1080/19378620903225059

Fox, M. F. (2010). Women and men faculty in academic science and engineering: Social organizational indicators and implications. American Behavioral Scientist, 53(7), 997-1012. https://doi. org/10.1177/0002764209356234

Hart, J. (2016). Dissecting a gendered organization: Implications for career trajectories for mid-career faculty women in STEM. The Journal of Higher Education, 87(5), 605-634. https://doi.org/10.1080/ $\underline{00221546.2016 .11777416}$

Heilman, M. E. (2001). Description and prescription: How gender stereotypes prevent women's ascent up the organizational ladder. Journal of Social Issues, 57(4), 657-674.

Isaac, C., Griffin, L., \& Carnes, M. (2010). A qualitative study of faculty members' views of women chairs. Journal of Women's Health, 19(3), 533-546. https:// doi.org/10.1089/jwh.2009.1506

Luna, G. (2012). Planning for an American higher education leadership crisis: The succession issue for administrators. International Leadership Journal, 4(1), 56-79.

Major, D. A., Morganson, V. J., \& Bolen, H. M. (2013). Predictors of occupational and organizational commitment in information technology: Exploring gender differences and similarities. Journal of Business and Psychology, 28, 301-314.

Marinelli, M., \& Lord, L. (2014). Onwards and upwards: Insights from women managers and leaders in engineering. In D. Bilimoria \& L. Lord (Eds.), Women in STEM careers: International perspectives on increasing workforce participation, advancement and leadership (pp. 101-123). Edward Elgar.

McCullough, L. (2011). Women's leadership in science, technology, engineering and mathematics: Barriers to participation. Forum on Public Policy Online, 2. https://eric.ed.gov/?id=EJ944199

Misra, J., Lundquist, J. H., Holmes, E., \& Agiomavritis, S. (2011). The ivory ceiling of service work. Academe, 97(1), 22-26.

Moss-Racusin, C. A., \& Rudman, L. A. (2010). Disruptions in women's self-promotion: The backlash avoidance model. Psychology of Women Quarterly, 34(2), 186-202.

Natural Sciences and Engineering Research Council. (2017). Women in science and engineering in Canada. NSERC.

Ornstein, M., Stewart, P., \& Drakich, J. (2007). Promotion at Canadian universities: The intersection of gender, discipline, and institution. Canadian Journal of Higher Education, 37(3), 1-25.

Parker, M., \& Welch, E. W. (2013). Professional networks, science ability, and gender determinants of three types of leadership in academic science and engineering. The Leadership Quarterly, 24, 332-348. https://www.doi.org/10.1016/j.leaqua.2013.01.001

Peter, T., Dengate, J., Farenhorst, A., \& FranzOdendaal, T. (2020). Department culture in Canadian sciences \& engineering: An empirical test of the Culture Conducive to Women's Academic Success model. NASPA Journal of Women and Gender in Higher Education, 13(2), 175-192. https://doi.org/1 $\underline{0.1080 / 26379112.2020 .1784753}$

Roos, P. A., \& Gatta, M. L. (2009). Gender (in)equality in the academy: Subtle mechanisms and the production of inequality. Research in Social Stratification and Mobility, 27, 177-200. https://www.doi. 


\section{org/10.1016/.irssm.2009.04.005}

Rosser, S. V. (2004). The science glass ceiling: Academic women scientists and the struggle to succeed. Routledge.

Rudman, L. A., Moss-Racusin, C. A., Phelan, J. E., \& Nauts, S. (2012). Status incongruity and backlash effects: Defending the gender hierarchy motivates prejudice against female leaders. Journal of Experimental Social Psychology, 48, 165-179. https:/l www.doi.org/10.1016/j.jesp.2011.10.008

Sagebiel, F. (2018). Gender and network awareness in/for successful leadership in academic science and engineering. International Journal of Gender, Science and Technology, 10(1), 24-51.

Settles, I. H., Cortina, L. M., Malley, J., \& Stewart, A. J. (2006). The climate for women in academic science: The good, the bad, and the changeable. Psychology of Women Quarterly, 30(1), 47-58. https://doi.org/10.1111/j.1471-6402.2006.00261.x

Settles, I. H., Cortina, L. M., Stewart, A. J., \& Malley, J. (2007). Voice matters: Buffering the impact of climate for women in science. Psychology of Women Quarterly, 31(3), 270-281.

Smith, M. S., \& Bray, N. (2017). The diversity gap in 2017. Academic Women's Association: University of Alberta.

Statistics Canada. (2018). University and colleges academic staff survey (UCASS). http://www23. statcan.gc.ca/imdb/p2SV.pl?Function=getSurvey\&ld=371910

Stenken, J. A., \& Zajicek, A. M. (2010). The importance of asking, mentoring, and building networks for academic career success - a personal and social science perspective. Analytical and Bioanalytical Chemistry, 396, 541-546. https://doi: $10.1007 /$ s00216-009-3275-X

Stout, J. G., Dasgupta, N., Hunsinger, M., \& McManus, M. A. (2011). STEMming the tide: Using ingroup experts to inoculate women's self-concept in science, technology, engineering, and mathematics (STEM). Journal of Personality and Social Psychology, 100(2), 255-270. https://doi.org/10.1037/ $\underline{\mathrm{a} 0021385}$
Tomàs, M., Lavie, J. M., del Mar Duran, M., \& Guillamon, C. (2010). Women in academic administration at the university. Educational Management Administration \& Leadership, 38(4), 487-498. https:/l www.doi.org/10.1177/1741143210368266

XU, Y. J. (2008). Gender disparity in STEM disciplines: A study of faculty attrition and turnover intentions. Research in Higher Education, 49(7), 607-624. https://www.doi.org/10.1007/s11162-008-9097-4

\section{Contact Information}

Jennifer Dengate

Jennifer.Dengate@umanitoba.ca 